\title{
A STUDY OF RENAL IMPAIRMENT IN HIV SEROPOSITIVE SUBJECTS ATTENDING ART CLINIC IN K. R. HOSPITAL, MYSORE
}

\author{
Laxme Gowda1, Ramesh S. S
}

${ }^{1}$ Associate Professor, Department of Medicine, Mysore Medical College and Research Institute, Mysore. ${ }^{2}$ Associate Professor, Department of Medicine, Mysore Medical College and Research Institute, Mysore.

\section{ABSTRACT}

\section{BACKGROUND}

The number of people living with HIV/AIDS is on the rise, so are the problems like renal dysfunction which needs to be addressed. The study was aimed at providing data regarding prevalence and the association of certain modifiable and non-modifiable factors with renal function.

\section{MATERIALS AND METHODS}

This was a cross-sectional study on 390 HIV positive subjects. Renal function was assessed by means of eGFR, calculated using Cockcroft-Gault equation and proteinuria, estimated by spot Urine Albumin Creatinine Ratio (UACR). Renal dysfunction was identified by either eGFR $<60 \mathrm{~mL} / \mathrm{min}$ or UACR $>30 \mathrm{mg} / \mathrm{gm}$. The data was analysed based on demographic characteristics, type and duration on ART, height, weight, body mass index, CD4 count, blood pressure and fasting lipid profile between renal dysfunction group and normal renal function group.

\section{RESULTS}

$21.3 \%(n=83)$ of study population had renal dysfunction. Sixty percent of them were females. Higher mean duration of ART (40.3 months) and lower mean CD4 counts (312.6 cells $\left./ \mathrm{mm}^{3}\right)$ was associated with renal dysfunction. Mean height $(162.6 \mathrm{~cm})$ and mean weight $(55.3 \mathrm{Kgs})$ were lower in renal dysfunction group and significant. Mean LDL cholesterol (100.3 mg/dL) and serum triglycerides (197.0 mg/dL) were higher among renal dysfunction group. Different types of ART regimen, BMI, blood pressure, HDL cholesterol and total cholesterol was found to have insignificant association in the study.

\section{CONCLUSION}

Every one in five HIV positive subjects might have renal insufficiency and more so common in females. Lower height, lower weight, increased duration of ART therapy were associated with decreased renal function and has to be screened. Different types of ART regimen, body mass index, systolic and diastolic blood pressure did not show any effect on renal function in this study. Decrease in CD4 count was shown to have positive correlation with decrease in estimated GFR. So subjects with greater immunosuppression should be screened frequently. High triglyceride levels and high LDL levels are associated with decreased renal function.

\section{KEYWORDS}

HIV Seropositivity; Renal Insufficiency; Proteinuria; CD4 Cell Count.

HOW TO CITE THIS ARTICLE: Gowda L, Ramesh SS. A study of renal impairment in HIV seropositive subjects attending ART clinic in K. R. Hospital, Mysore. J. Evolution Med. Dent. Sci. 2017;6(18):1391-1396, DOI: 10.14260/Jemds/2017/304

\section{BACKGROUND}

Human Immunodeficiency Virus (HIV) was identified in 1983 as a causative agent for Acquired Immunodeficiency Syndrome (AIDS). ${ }^{1}$ This virus progressively damages cells of the body's immune system thus predisposing the infected individual to opportunistic infections, cancers and different organ pathology.

In 1984 Rao et $\mathrm{al}^{2}$ reported a renal lesion in patients infected with HIV that was characterised with severe proteinuria, biochemical features of nephritic syndrome and renal function impairment that rapidly progresses to end stage renal disease. Various types and severities of renal

Financial or Other, Competing Interest: None.

Submission 02-02-2017, Peer Review 18-02-2017,

Acceptance 21-02-2017, Published 02-03-2017.

Corresponding Author:

Laxme Gowda,

Associate Professor,

Department of Medicine,

Mysore Medical College and Research Institute,

Mysore.

E-mail: laxmegowda@gmail.com

DOI: $10.14260 /$ jemds $/ 2017 / 304$ disorders have been encountered at all stages of HIV infections, ranging from mild and transient renal impairment to end stage renal disease requiring renal replacement therapy. ${ }^{3}$ The CD 4 cell count is used as a surrogate marker of immune status in HIV infected patients. However, infection with HIV leads to destruction and depletion of CD4 cells and this predisposes the individual to various disease conditions. CD4 cell count has been used to monitor, follow up and determine the severity of HIV infection. ${ }^{4}$

The Renal Function Impairment (RFI) has been encountered at various stages of HIV infection from the stage of seroconversion to advanced AIDS. The prevalence, severity, morbidity and mortality of renal function impairment in these patients have been associated with the degree of immunosuppression.5,6 Various studies have reported that CD4 cell count of less than $200 / \mathrm{uL}$ is a poor prognostic index in HIV infected patients with renal disease.7,8 Early detection and intervention delays progression and in many situations, reverses impairment of renal function in HIV infected patients. The CD4 cell count of HIV infected patients is assessed on presentation in most health facilities. However, renal function assessment is sparse in most of the centres in attending to HIV patients. It is 
necessary to objectively assess the relationship between renal function and degree of immunosuppression in these patients.

Renal function is usually assessed by means of serum creatinine measurement and then estimated glomerular filtration rate calculation by Cockroft-Gault formula or Modification of Diet in Renal Disease equation (MDRD). ${ }^{9}$ Proteinuria and persistent microalbuminuria is also used for assessing renal function. Urine albumin creatinine ratio, which is a surrogate marker for microalbuminuria can detect early renal dysfunction patients.

Other determinants which contribute to renal dysfunction may include comorbidities such as hypertension, diabetes, hyperlipidaemia, age, sex and ethnicity.10,11,12 It might also be affected by many opportunistic infections, duration of HAART, type of drug regimen as shown in many previous studies. ${ }^{13,14}$

Most of the studies regarding renal impairment in HIV patients have been done outside India and data regarding prevalence and pattern of renal involvement and its correlation with various variables in this part of India is not available. So the aim of this study is to provide valuable data regarding renal dysfunction in HIV infected individuals.

\section{Objectives}

1. To determine the prevalence of renal impairment in HIV seropositive subjects attending ART Clinic in $\mathrm{K}$. R. Hospital, Mysore.

2. To determine the association between renal impairment and variables such as age, sex, body mass index, blood pressure, CD4 count, type of ART regimen, duration of ART and lipid profile.

\section{MATERIALS AND METHODS}

\section{Source of Data}

The material for the study will be collected from subjects who are HIV seropositive and who fulfil the inclusion and exclusion criteria, attending ART Clinic, K. R. Hospital, Mysore.

\section{Method of Collection of Data \\ Study Design}

Single centred cross-sectional study in a tertiary care hospital.

\section{Sample Size}

390 (As reviewed with statistician).

\section{Sampling Method}

Simple Random Sampling.

\section{Duration of Study}

January 2014 to August 2015.

\section{Method of Collection of Specimens and Processing}

Blood and urine sample will be collected at a single sitting with universal precautions into separate sterile containers. Blood sample will be used for testing CD4 count, haemoglobin, total count using automated counters and used to test serum creatinine by Jaffe method. Urine sample will be tested for urine albumin creatinine ratio by immunoturbidimetric method.

\section{Inclusion Criteria}

1. HIV seropositive subjects attending ART Clinic, K. R. Hospital.

2. Age more than or equal to 18 years.

3. Subjects either on antiretroviral therapy or not on any drug therapy.

\section{Exclusion Criteria}

1. Subjects with pre-existing urinary tract infection.

2. Pregnancy.

3. Subjects not willing to take part in the study.

4. Patients on steroid intake or antituberculous treatment.

\section{Investigations}

- Haemoglobin.

- Urine Albumin-Creatinine Ratio (Urine ACR).

- Blood urea and serum creatinine.

- CD4 cell count.

- Lipid profile.

- RBS (Random Blood Sugar).

- LFT (Liver Function Test).

- White blood cell count.

Data were collected using a pretested proforma meeting the objectives of the study. Detailed history, physical examination and necessary investigation were undertaken. The purpose of the study were explained to the patient and informed consent obtained.

After collecting data subjects will be assessed for renal function impairment based on two criteria given below and classified into two groups, one with renal dysfunction and one with normal renal function. If a study subject satisfies any one of these two criteria, he/she will be considered to have renal function impairment or renal dysfunction.

Criteria are - 1.) Estimated GFR $<60 \mathrm{~mL} / \mathrm{min}$ as calculated using Cockcroft-Gault formula and 2.) Microalbuminuria or Macroalbuminuria based on urine albumin creatinine ratio (UACR) $>30 \mathrm{mg} / \mathrm{gm}$. The prevalence of renal dysfunction will be found out using this definition and the rest of the data were used for further analysis and interpretation.

\section{Data Analysis and Interpretation}

Data was entered into Microsoft Excel and analyses were done using the Statistical Package for Social Sciences (SPSS) for Windows Software (version 18.0; SPSS Inc., Chicago). Descriptive statistics such as Mean and Standard Deviation (SD) for continuous variables and frequency and percentage for categorical variables were determined. The level of significance was set at 0.05 . Correlation analysis will be done wherever appropriate.

\begin{tabular}{|c|c|c|c|c|c|c|}
\hline BMI Distribution & Number of Patients & Mean BMI & Minimum BMI & Maximum BMI & Standard Deviation & P-value \\
\hline Normal patients & 307 & 21.27 & 15.17 & 27.94 & 1.92 & 0.16 \\
\hline Renal dysfunction patients & 83 & 20.94 & 16.26 & 25.39 & 1.97 & 0.16 \\
\hline \multicolumn{7}{|c|}{ Table 1. Body Mass Index Distribution } \\
\hline
\end{tabular}


Mean BMI is statistically same among normal patients and also patients with renal dysfunction with $\mathrm{p}$-value of 0.16 . The pvalue is statistically insignificant at $5 \%$ significance level. It indicates that the mean BMI is statistically same across both the groups.

\begin{tabular}{|c|c|c|c|c|c|}
\hline SBP Distribution & Mean SBP & Minimum SBP & Maximum SBP & Standard Deviation & P-value \\
\hline Normal patients & 124.63 & 108 & 154 & 8.62 & 0.232 \\
\hline Renal dysfunction patients & 126.19 & 12 & 150 & 15.71 & 0.23 \\
\hline \multicolumn{7}{|c|}{ Table 2. Systolic BP Distribution } \\
\hline
\end{tabular}

Mean SBP is statistically same among normal patients and also patients with renal dysfunction with $\mathrm{p}$-value of 0.232 . The $\mathrm{p}$ value is statistically insignificant at $5 \%$ significance level. It indicates that the mean SBP is statistically same across both the groups.

\begin{tabular}{|c|c|c|c|c|c|}
\hline DBP Distribution & Mean DBP & Minimum DBP & Maximum DBP & Standard Deviation & P-value \\
\hline Normal patients & 74.90 & 62 & 90 & 5.57 & 0.204 \\
\hline Renal dysfunction patients & 75.78 & 68 & 90 & 5.75 & 0.204 \\
\hline \multicolumn{7}{|c|}{ Table 3. Diastolic BP Distribution } \\
\hline
\end{tabular}

Mean DBP is statistically same among normal patients and also patients with renal dysfunction with $\mathrm{p}$-value of 0.204 . The $\mathrm{p}$ value is statistically insignificant at $5 \%$ significance level. It indicates that the mean DBP is statistically same across both the groups.

\begin{tabular}{|c|c|c|c|c|c|}
\hline CD4 CT Distribution & Mean CD4 CT & Minimum CD4 CT & Maximum CD4 CT & Standard Deviation & P-value \\
\hline Normal patients & 393.49 & 21 & 1398 & 216.01 & 0.002 \\
\hline Renal dysfunction patients & 312.61 & 32 & 1163 & 206.86 & 0.063 \\
\hline \multicolumn{7}{|c|}{ Table 4. CD4 Count Distribution }
\end{tabular}

Mean CD4 count is statistically different among both the groups with p-value of 0.002 . The p-value indicates the significant difference in the mean CD4 count across both the groups. The result indicates that the CD4 count is statistically lower among patients with renal dysfunction.

\begin{tabular}{|c|c|c|c|c|c|}
\hline Serum Cholesterol & Mean T.Ch & Minimum T.Ch & Maximum T.Ch & Standard Deviation & P-value \\
\hline Normal patients & 184.39 & 106 & 355 & 33.05 & 0.667 \\
\hline Renal dysfunction patients & 186.27 & 96 & 341 & 42.62 & 0.62 \\
\hline \multicolumn{7}{|c|}{ Table 5. Serum Cholesterol Distribution } \\
\hline
\end{tabular}

P-value of 0.667 suggests that mean Serum total cholesterol is statistically same at $5 \%$ significance level.

\begin{tabular}{|c|c|c|c|c|c|}
\hline Serum Triglycerides & $\begin{array}{c}\text { Mean Serum } \\
\text { Triglycerides }\end{array}$ & $\begin{array}{c}\text { Minimum Serum } \\
\text { Triglycerides }\end{array}$ & $\begin{array}{c}\text { Maximum Serum } \\
\text { Triglycerides }\end{array}$ & $\begin{array}{c}\text { Standard } \\
\text { Deviation }\end{array}$ & $\begin{array}{c}\text { P- } \\
\text { value }\end{array}$ \\
\hline Normal patients & 163.72 & 13 & 488 & 64.67 \\
\hline Renal dysfunction patients & 197.02 & 84 & 580 & 88.84 \\
\hline \multicolumn{7}{|r|}{ Table 6. Serum Triglycerides Distribution } \\
\hline
\end{tabular}

Mean Serum triglycerides is statistically different at $5 \%$ significance level with $\mathrm{p}$-value of 0.0 . It indicates the mean of Serum triglycerides is different and it is significantly higher among the patients with renal dysfunction.

\begin{tabular}{|c|c|c|c|c|c|c|}
\hline HDL Distribution & Number of Patients & Mean HDL & Minimum HDL & Maximum HDL & Standard Deviation & P-value \\
\hline Normal patients & 307 & 42.70 & 3 & 70 & 7.44 & 0.396 \\
\hline Renal dysfunction patients & 83 & 43.52 & 27 & 88 & 9.07 \\
\hline \multicolumn{7}{|r|}{ Table 7. High Density Lipoprotein Distribution } \\
\hline
\end{tabular}

Mean HDL is statistically same among normal patients and also patients with renal dysfunction with $\mathrm{p}$-value of 0.396 . The $\mathrm{p}$ value is statistically insignificant at $5 \%$ significance level. It indicates that the mean HDL is statistically same across both the groups.

\begin{tabular}{|c|c|c|c|c|c|}
\hline LDL Distribution & Mean LDL & Min. LDL & Max. LDL & Standard Deviation & P-value \\
\hline Normal patients & 95.143 & 25 & 153 & 14.77 & \multirow{2}{*}{0.005} \\
\hline Renal dysfunction patients & 100.253 & 66 & 151 & 14.20 & \\
\hline \multicolumn{7}{|c|}{ Table 8. Low Density Lipoprotein Distribution } \\
\hline
\end{tabular}

Mean LDL is statistically different among both the groups with p-value of 0.05 at $5 \%$ significance level. It indicates that mean LDL is statistically higher among the patients with renal dysfunction.

\begin{tabular}{|c|c|c|c|}
\hline \multicolumn{4}{|c|}{ Correlation Analysis Results } \\
\hline & & UACR & eGFR \\
\hline \multirow{3}{*}{ CD4 CT } & Correlation value & -0.081 & 0.171 \\
\hline & P-value & 0.112 & 0.001 \\
\hline & Number of patients & 390 & 390 \\
\hline
\end{tabular}


There is negative association between UACR and CD4 counts. The strength of association between UACR and CD4 counts is very low $(\mathrm{r}=-0.081, \mathrm{p}=0.112)$ and is statistically insignificant at $5 \%$ significance level.

The strength of association between CD4 count and eGFR is low ( $r=0.171, p=0.001)$, but is statistically significant at $5 \%$ significance level. So decline in eGFR is associated with decline in CD4 count.

\section{DISCUSSION}

In this study conducted in ART Clinic, K. R. Hospital, 390 subjects fulfilling inclusion and exclusion criteria were included. Out of them, 83 subjects $(21.28 \%)$ were found to have renal dysfunction according to the criteria used. Renal function impairment was identified based on two criteria, first one was estimated GFR $<60 \mathrm{~mL} / \mathrm{min}$ calculated using Cockcroft-Gault formula and second one was microalbuminuria based on urine albumin-creatinine ratio $>$ $30 \mathrm{mg} / \mathrm{gm}$. Patient was considered to have renal dysfunction if any one of the criteria was fulfilled.

Out of the $21.28 \%$ subjects with renal function impairment, $10 \%$ had only low eGFR, $8.2 \%$ had only microalbuminuria and $3.08 \%$ had both decreased eGFR and microalbuminuria. Prevalence of renal function impairment varies from as low as $6 \%$ to high as $31 \%$ in other studies. Study by Keith Rawlings et al ${ }^{15}$ in USA had a prevalence of $6 \%$. A study by Menezes et $\mathrm{al}^{10}$ in Brazil on HIV infected subjects with low viral load and CD4 count above 200 cells $/ \mathrm{mm}^{3}$ showed a prevalence of $8.4 \%$.

Another study by Okafor et $\mathrm{al}^{5}$ in Nigeria had higher prevalence of renal dysfunction in the range of $31 \%$. Another study by Overton et al ${ }^{11}$ in USA had a prevalence of $7.5 \%$. A study by Kamga et $\mathrm{al}^{16}$ in Cameroon had a prevalence of $30.45 \%$. The rest of the discussion has been done under the different factors studied.

\section{Age}

Patients were distributed from age 18 to 66 years. Normal renal function group and renal dysfunction group were divided into 5 age classes. It was found that almost $80 \%$ of subjects in normal renal function group were between age group 28 to 47 and $50.16 \%$ of the subjects in the renal dysfunction group were in the age group 38 to 47 .

Mean age was 42.4 years in normal function group, whereas it was 41.8 years in renal dysfunction group.

In a study conducted by Okafor et $\mathrm{al}^{5}$ (2007) in Nigeria showed mean age as 36.7 years in normal function subjects and 36.15 years in renal dysfunction subjects. In another study by Menezes et al ${ }^{10}$ (2009) in Brazil showed mean age in renal dysfunction patients as $45.6(\mathrm{SD}=11.5)$ years.

\section{Gender}

In the present study, males constituted $56.15 \%(n=219)$ and females $43.8 \%(n=171)$. In normal renal function subjects, females were $39.41 \%(n=121)$ and $60.24 \%(n=50)$ in renal dysfunction subjects. So, present study shows preponderance for females for renal impairment. It is against what was shown in a study by Overton et al ${ }^{11}$ (2009) in USA, which showed males $60.9 \%$ in normal function group and $67.4 \%$ males in renal impairment group. In another study by Struik et al $^{17}$ (2011) in Malawi showed $67.7 \%$ and $62.6 \%$ females in normal function and renal dysfunction group respectively.

\section{ART Regimen}

In this study subjects were divided into 4 groups based on their ART regimen namely Stavudine regimen, Tenofovir regimen, Zidovudine regimen and subjects who were not initiated on ART. The proportions of patients with renal dysfunction across the different regimens were statistically same with $\mathrm{p}$ value greater than 0.05 at $5 \%$ significance level. So no statistically significant difference was seen between various regimens and renal dysfunction.

This was consistent with studies conducted by Keith Rawlings et al ${ }^{15}$ (2009) in USA and Kamga HMF et al ${ }^{16}$ (2011) in Cameroon, which showed no difference with different ART regimens. But study conducted by Menezes et al ${ }^{10}$ (2009) showed tenofovir use as a risk factor for renal impairment.

\section{Duration of ART}

In the present study, mean duration of ART among normal renal function subjects were 30.9 (SD $=27.9$ ) months and among renal dysfunction subjects were 40.3 (SD $=31.1$ ) months. Mean ART duration in both the groups is statistically different with $\mathrm{p}$ value $=0.008$. It indicates that the mean duration on ART is statistically higher among renal dysfunction patients.

In the study conducted in Brazil by Menezes et al, ${ }^{10}$ mean time on antiretroviral therapy was $7.8(\mathrm{SD}=4.8)$ years and it was found that increased duration of therapy to be significantly associated risk factor for chronic kidney disease (Risk Ratio $=1.15, \mathrm{p}$-value $=0.011)$. In another followup study by Keith Rawlings et al ${ }^{15}$ also showed increase in duration of ART was associated with progressive decline in estimated glomerular filtration rate.

\section{Height}

In this study mean height was $164.4(\mathrm{SD}=6.75) \mathrm{cms}$ in normal renal function subjects and $162.6(\mathrm{SD}=7.02) \mathrm{cms}$ in renal dysfunction subjects. $\mathrm{P}$ value was 0.032 , which is significant at $5 \%$ significance level. So, less height was statistically associated with renal dysfunction, i.e. decrease in eGFR.

\section{Weight}

In this study mean weight was $57.5(\mathrm{SD}=6.02)$ Kgs in normal renal function subjects and $55.3(\mathrm{SD}=6.04) \mathrm{Kgs}$ in renal dysfunction subjects. $P$ value was 0.004 , which is significant at $5 \%$ significance level. Decline in renal function was significantly associated with less weight. This result is consistent with the study by Menezes et al $^{10}$ in Brazil, where higher weight was significantly associated with normal kidney function ( $R R=0.89, \mathrm{p}=0.005)$. In the study by Struik et $\mathrm{al}^{17}$ also lower weight was associated with lower eGFR.

\section{Body Mass Index (BMI)}

Present study showed mean BMI among normal renal function subjects slightly higher, i.e. $21.3(S D=1.92)$ than among renal dysfunction subjects, mean being 20.9 (SD = 1.97). But further analysis showed it was not statistically significant, $\mathrm{p}$ value being 0.16 . In a study by Overton et $\mathrm{al}^{11}$ also it was shown there was no significant association between BMI and renal dysfunction. 


\section{Blood Pressure}

In the present study mean Systolic Blood Pressure (SBP) among normal renal function subjects and renal dysfunction subjects were $124.6(\mathrm{SD}=8.6)$ and 126.2 ( $\mathrm{SD}=15.7) \mathrm{mmHg}$ respectively. It was found to be statistically insignificant, $p$ value $=0.232$. Mean Diastolic Blood Pressure (DBP) was 74.9 $(\mathrm{SD}=5.6)$ and $75.8(\mathrm{SD}=5.8)$ among normal function group and renal dysfunction group respectively. It was also found to be insignificant, $\mathrm{p}$ value being 0.204 . These findings were consistent with studies by Struik et al ${ }^{17}$ in Malawi, Okafor et $\mathrm{al}^{5}$ in Nigeria and Han et $\mathrm{al}^{18}$ in South Africa, which showed no statistically significant difference in blood pressure between the two groups.

\section{CD4 Count}

In the present study, mean CD4 count was $393.5(\mathrm{SD}=216)$ cells among normal renal function group and 312.6 (SD = 206.9) cells among renal dysfunction group. The difference was found to be statistically significant, $\mathrm{p}$ value being 0.002 . So lower CD4 count is associated with impaired renal function. In the study by Struik et al, ${ }^{17}$ lower mean CD4 count was associated with lower eGFR and in a study by Overton et al ${ }^{11}$ showed low nadir CD4 count was associated with low eGFR. But in a study by Kamga et al,16 no significant association was demonstrated between low CD4 count and low eGFR. CD4 count showed positive correlation with eGFR $(r=0.171, p$ value $=0.001)$, i.e. with decrease in CD4 count there will be decrease in eGFR. CD4 count showed negative correlation with Urine Albumin Creatinine Ratio (UACR), but it was found to be statistically insignificant $(r=-0.081, p$ value $=0.112$ ). In a study by Okafor et al, 5 it was shown that decrease in CD4 count had positive correlation $(r=0.46, p$ value $=0.031$ ) with severity of renal function impairment.

\section{Lipid Profile}

In this study, mean total cholesterol was 184.9 (SD = 33.05) $\mathrm{mg} / \mathrm{dL}$ and 186.2 (SD = 42.62) $\mathrm{mg} / \mathrm{dL}$ among normal and renal dysfunction group respectively. The difference was statistically insignificant, $\mathrm{p}$ value $=0.667$. Mean triglyceride values were $163.7(\mathrm{SD}=64.7) \mathrm{mg} / \mathrm{dL}$ and $197.0(\mathrm{SD}=88.8)$ $\mathrm{mg} / \mathrm{dL}$ respectively and $\mathrm{p}$ value was 0.00 . So higher triglyceride value was associated with renal dysfunction. The difference in mean HDL value of $42.7(\mathrm{SD}=7.4) \mathrm{mg} / \mathrm{dL}$ among normal renal function group and 43.5 (SD =9.0) among renal dysfunction group was found to be statistically insignificant, $\mathrm{p}$ value $=0.396 . \mathrm{LDL}$ means were $95.1(\mathrm{SD}=$ 14.8) $\mathrm{mg} / \mathrm{dL}$ and 100.3 (SD = 14.2) $\mathrm{mg} / \mathrm{dL}$ among normal and renal dysfunction group and was found to be statistically significant, $\mathrm{p}$ value $=0.005$.

In the study by Overton et al $^{11}$ conducted among 845 subjects in USA, it was found that higher total cholesterol and higher triglyceride level was associated with decline in renal function, whereas HDL and LDL level did not show any significant association.

\section{CONCLUSION}

1. A total of $390 \mathrm{HIV}$ infected subjects were included in the study.

2. The prevalence of renal dysfunction in the study was $21.28 \%(n=83)$. So around one-fifth of HIV infected patients will have renal function impairment.
3. Around half of the renal dysfunction subjects (50.16\%) were in the age group 38 - 47 years.

4. Though the study population was predominantly males, $60.24 \%$ of the renal dysfunction group was females.

5. HIV positive patients whether pre-ART or on different ART regimens did not have any implication on renal function.

6. There is increased chance of renal function impairment with increased duration of antiretroviral therapy.

7. Lesser height and weight is associated with more chance of renal dysfunction.

8. Body mass index did not show any significant effect on renal function.

9. Systolic and diastolic blood pressure did not show any association with renal dysfunction in this study.

10. Lower CD4 count, which indicates more immunosuppression is associated with decreased renal function and more so with decline in estimated GFR rather than proteinuria.

11. Abnormal lipid profile in the form of high triglycerides and high LDL contributes to renal function impairment.

\section{Summary}

HIV infected population and AIDS is a global health concern and more so in a populated country like India. With increasing awareness and advent of ART the number of people living with HIV/AIDS is on the rise, so are the problems like renal dysfunction which needs to be addressed. The study was aimed at providing data regarding prevalence and the association of certain modifiable and non-modifiable factors with renal function.

The study was conducted in ART Clinic, K. R. Hospital, Mysore. A total of 390 subjects were studied and prevalence of renal dysfunction was found to be $21.28 \%$. Around $3 / 5^{\text {th }}$ of renal dysfunction population were females. Lower height, lower weight, increased duration of ART therapy were associated with decreased renal function. Different types of ART regimen, body mass index, systolic and diastolic blood pressure did not show any effect on renal function in this study.

Decrease in CD4 count was shown to have positive correlation with decrease in estimated GFR. High triglyceride levels and high LDL levels are associated with decreased renal function.

\section{REFERENCES}

[1] Barré-Sinoussi F, Chermann JC, Rey F, et al. Isolation of a T-lymphotropic retrovirus from a patient at risk for acquired immune deficiency syndrome (AIDS). Science 1983;220(4599):868-71.

[2] Rao TK, Fillippone EJ, Nicastri AD, et al. Associated focal and segmental glomerulosclerosis in acquired immunodeficiency syndrome. $\mathrm{N}$ Engl $\mathrm{J}$ Med 1984;310(11):669-73.

[3] Roling J, Schmid H, Fischereder M, et al. HIVassociated renal diseases and highly active antiretroviral therapy induced nephropathy. Clin Infect Dis 2006;42(10):1488-95.

[4] Abbar AK. Diseases of immunity: AIDS. In: Robbins and Cotron pathologic basis of diseases. $7^{\text {th }}$ edn. 2004:245-65. 
[5] Okafor UH, Unuigbe EI, Ojogwu LI, et al. Renal disease in HIV infected patients at university of benin teaching hospital in Nigeria. Afr Health Sci 2011;11(Suppl 1):S28-33.

[6] Winston JA, Klotman ME, Klotman PE. HIV associated nephropathy is a late, not early, manifestation of HIV1 infection. Kidney Int 1999;55(3):1036-40.

[7] Reid A, Stohr W, Walker AS, et al. Severe renal dysfunction and risk factors associated with renal impairment in HIV infected adults in Africa initiating antiretroviral therapy. Clin Infect Dis 2008;46(8):1271-81.

[8] Winston JA, Burns GC, Klotman PE. The human immunodeficiency virus (HIV) epidemic and HIVassociated nephropathy. Semin Nephrol 1998;18(4):373-7.

[9] Joanne MB, Skorecki K. Chronic kidney disease. In: Longo DL, Fauci AS, Kasper DL, et al. (eds). Harrison's principles of internal medicine. $18^{\text {th }}$ edn. New York The McGraw Hill Companies, Inc 2012:2308-21.

[10] Menezes AM, Torelly J, Real L, et al. Prevalence and risk factors associated to chronic kidney disease in HIV-infected patients on HAART and undetectable viral load in Brazil. PLoS One 2011;6(10):e26042.

[11] Overton ET, Nurutdinova D, Freeman J, et al. Factors associated with renal dysfunction within an urban HIV infected cohort in the era of HAART. HIV Med 2009;10(6):343-50.
[12] Cantor ES, Kimmel PL, Bosch JP. Effect of race on expression of acquired immunodeficiency syndromeassociated nephropathy. Arch Intern Med 1991;151(1):125-8.

[13] Flandre P, Pugliese P, Cuzin L, et al. Risk factors of chronic kidney disease in HIV-infected patients. Clin J Am Soc Nephrol 2011;6(7):1700-7.

[14] Schwartz EJ, Szczech LA, Ross MJ, et al. Highly active antiretroviral therapy and the epidemic of HIV+ endstage renal disease. J Am Soc Nephrol 2005;16(8):2412-20.

[15] Rawlings MK, Jennifer K, Edna PK, et al. Impact of comorbidities and drug therapy on development of renal impairment in a predominantly African American and hispanic HIV clinic population. HIV AIDS (Auckl) 2011;3:1-8.

[16] Kamga HLF, Assob JCN, Njunda AL, et al. The kidney function trends in human immunodeficiency virus/AIDS patients at the Nylon District hospital, Douala, Cameroon. Journal of AIDS and HIV Research 2011;3(2):30-7.

[17] Struik GM, den Exter RA, Munthali C, et al. The prevalence of renal impairment among adults with early HIV disease in Blantyre, Malawi. Int J STD AIDS 2011;22(8):457-62.

[18] Han TM, Naicker S, Ramdial PK, et al. A cross sectional study of HIV seropositive patients with varying degrees of proteinuria in South Africa. Kidney Int 2006;69(12):2243-50. 